Cordini, N. S. Delito y pena en la teoría de la imputación según Hegel. Derecho y Ciencias Sociales. Noviembre 2019 - Abril 2020 N ${ }^{\circ}$

22. Pgs 18 - 39 ISNN 1852-2971 Instituto de Cultura Jurídica y Maestría en Sociología Jurídica. FCJ y S. UNLP

\title{
Delito y pena en la teoría de la imputación según Hegel
}

Crime and Punishment in the Theory of Imputation according to Hegel

\section{Nicolás Santiago Cordini ${ }^{\bullet}$}

\section{Resumen}

La necesidad de volver a poner en discusión el modelo de imputación de Hegel viene de la mano del desarrollo de nuevos modelos de comprensión cuyos conceptos se acercan a la filosofía por él desarrollada. Objeto del presente trabajo será analizar algunos aspectos sobresalientes de la teoría hegeliana de la imputación, haciendo énfasis en aquellas cuestiones que singuen siendo son objeto de debate y, a su vez, trazar la relación sinalagmática entre delito, imputación y pena pues abordar estos conceptos de manera aislada, conllevan una visión parcial y sesgada del sistema hegeliano de imputación.

Palabras claves: delito; imputación; pena; Hegel

\begin{abstract}
The need to put back under discussion the model of imputation of Hegel goes in hand in hand with a new model of understanding whose concepts approach to the philosophy developed by him. Subject of the present paper will be to analyse some prominent features of the Hegelian theory of imputation, emphasizing in that question that remain a matter of discussion and, in turn, to draw the mutual relationship between crime, imputation and punishment because tackling these concepts in isolation leads to a partial and biased view of the Hegelian system of imputation.
\end{abstract}

Key words: crime, imputation, punishment, Hegel

\footnotetext{
- Abog. especialista en Derecho penal, magister y doctor en Derecho. Investigador CONICET en el Instituto A. L. Gioja, Facultad de Derecho, Universidad de Buenos Aires. Profesor de Derecho penal de la Facultad de Ciencias Jurídicas y Sociales de la Universidad Nacional del Litoral. nicocordini@yahoo.com.ar
}

Recibido: 26/9/2018. Publicable con correcciones: 24/10/2019 
Cordini, N. S. Delito y pena en la teoría de la imputación según Hegel. Derecho y Ciencias Sociales. Noviembre $2019-\mathrm{Abril}_{2020}{ }^{\circ}$ 22. Pgs 18 - 39 ISNN 1852-2971 Instituto de Cultura Jurídica y Maestría en Sociología Jurídica. FCJ y S. UNLP

\section{Delito y pena en la teoría de la imputación según Hegel}

\section{Nicolás Santiago Cordini}

\section{Introducción}

La 'teoría de la imputación' (Zurechnungslehre) ${ }^{1}$ sostenida por Hegel se desarrolló en el período previo al establecimiento de la dogmática jurídico-penal como disciplina científica $\mathrm{y}$, con ella, la aceptación de la 'teoría del delito' (Verbrechenslehre) como categoría de análisis de carácter central, siendo abandonadas y tachadas de acientíficas las antiguas doctrinas de la imputación y, entre ellas, el modelo hegeliano. La necesidad de volver a poner en discusión un modelo científicamente superado viene de la mano del desarrollo de nuevos modelos de comprensión cuyos conceptos se acercan a la filosofía desarrollada por Hegel. Entre éstos el que más ha tenido difusión en el ámbito latinoamericano es el propuesto por Günther Jakobs (2012: 15-16), aunque existen otros autores en esta línea, tales como Heiko Lesch (1999 a) o Michael Pawlik (2012). Objeto del presente trabajo será analizar algunos aspectos sobresalientes de la teoría hegeliana de la imputación, haciendo énfasis en aquellas cuestiones que aún son objeto de debate y, a su vez, trazar la relación sinalagmática entre delito, imputación y pena, puesto que sólo a partir de la relación de estos tres conceptos en el sistema hegeliano es posible abordar de manera cabal este modelo de imputación jurídico-penal.

\section{EI Derecho penal a la luz del método de la Filosofía del Derecho}

Hegel emprende la tarea de superar la dicotomía entre un derecho natural atemporal y

\footnotetext{
${ }^{1}$ Cuando hablamos de las teorías de la imputación, concepto de imputación en sentido amplio, o también de un sistema de imputación total, estamos aludiendo a un concepto que no se circunscribe a la determinación de los resultados atribuibles al sujeto (imputación objetiva del resultado), sino que comprende al delito como una totalidad. A saber, a la atribución del injusto culpable. Para estos modelos es materia de imputación tanto la atribución del hecho ilícito como así también la atribución del hecho como culpable.Conforme al concepto amplio de imputación, ésta debe ser entendida como un juicio mediante el cual un determinado suceso, sea un movimiento corporal o un sonido, es considerado un hecho, o sea, una acción del sujeto imputado. Acción que es atribuida nuevamente al sujeto como 'culpable', en la medida que el actor no haya seguido el deber que la norma le imponía. Modelos de imputación total son los propuestos por Kant (1797: 227) y Hegel (1820). En el siglo $\mathrm{xx}$, luego de la instauración de la teoría del delito como modelo de compresión dominante diversos autores han adherido a la idea de la imputación en sentido amplio así, Werner Hardwig (1957), Joachim Hruschka (1976; 1991) y Günther Jakobs (2012),entre otros. Lo que comparten estos modelos teóricos es considerar a la imputación como la totalidad del delito. Objeto de imputación es tanto el ilícito como la culpabilidad. Ahora bien, las diferentes teorías que se enrolan en esta corriente difieren en el grado en que se apartan de las categorías aportadas por la tradicional teoría del delito, como así también en el contenido y en el grado de independencia entre los diversos juicios de imputación.
} 
Cordini, N. S. Delito y pena en la teoría de la imputación según Hegel. Derecho y Ciencias Sociales. Noviembre $2019-\mathrm{Abril}_{2020}{ }^{\circ}$ 22. Pgs 18 - 39 ISNN 1852-2971 Instituto de Cultura Jurídica y Maestría en Sociología Jurídica. FCJ y S. UNLP

ahistórico y un derecho positivo relativo o hipotético. Para ello, propone fundir la conceptualidad intemporal y la mutación histórica a través un proceso que tiene lugar en el 'ahora' temporal, en el cual el desarrollo del concepto entra en un paralelismo con el desarrollo temporal. ${ }^{2} \mathrm{~A}$ esta estructura dinámica Hegel la encuentra en la 'dialéctica' (Welzel, 2005:237).

La Filosofía del Derecho (1820) de Hegel transita dialécticamente por tres niveles diversos, ellos son: el Derecho abstracto (abstraktes Recht), la moralidad (Moralität) o moralidad subjetiva y la eticidad (Sittlichkeit) o moralidad objetiva. El Derecho abstracto y la moralidad no son aislables, existentes independientemente, ni comprensibles para sí como partes de la Filosofía del Derecho, sino sólo momentos de una unidad superior(Hegel, 1820: $\S 19,30)$, pues son finalmente anulados en la esfera de la eticidad (Larenz, 1930: 250) (Lesch, 1999a: 106).La dialéctica es así, el propio movimiento inmanente de los conceptos. $\mathrm{Su}$ especial significado yace allí, en que ella comprende para distinguir, no para separar, en la medida que relativiza las contradicciones y las neutraliza en conceptos más elevados.

La hasta entonces distinción kantiana entre actuar moral y mera conformidad al deber es suprimida porHegel, ${ }^{3}$ puesto que, para él,Derecho y moral son idénticos, una 'unidad general' (übergreifende Einheit). La moralidad como consciencia moral subjetiva y como opinión privada, y el Derecho abstracto como declaración de aquellas formas de vida externa, son sólo estadios dialécticos, pues en la eticidad tiene lugar la síntesis de la objetividad del Derecho abstracto y la de la subjetivad moral. La eticidad, como estadio último en la dialéctica del movimiento, es objetivada. Este proceso reflexivo de ninguna manera implica que la eticidad sea algo posterior al Derecho abstracto y a la moralidad, sino más bien que la eticidad es el 'fundamento' del Derecho abstracto y de la moralidad (Hegel, 1830c: $§ 408$ adición, 171). La eticidad comprende todas aquellas instituciones de los seres humanos, las cuales la consciencia general (Gattungs vernunft) lleva a su realización en la convivencia externa, en la que, por lo tanto, se acentúa uniformemente su carácter jurídico y moral. De esta manera, Derecho y moralidad objetiva no son, como en Kant, un 'deber ser' (Sollen), sino un 'ser' (Sein), una "realidad histórica concreta"(Bubnoff, 1966: 40).

Hegel aborda el Derecho penal en los tres niveles del sistema dialéctico, y no sólo en los

\footnotetext{
${ }^{2}$ Tanto el desarrollo temporal como el desarrollo del concepto están sujetos a la misma ley de la dialéctica.(Hegel, 1820: § 1, 18; § 22, adición, 39).

${ }^{3}$ En términos de Kant: "la conformidad o la no conformidad pura y simple de una acción con la ley, sin tener en cuenta sus motivos, se llama legalidad (conformidad a la ley). Pero esta conformidad, en la cual la idea del deber deducida de la ley es al mismo tiempo un móvil de acción, es la moralidad (Sittlichkeit) de la acción"(1797: 219).
} 
Cordini, N. S. Delito y pena en la teoría de la imputación según Hegel. Derecho y Ciencias Sociales. Noviembre $2019-\mathrm{Abril}_{2020}{ }^{\circ}$ 22. Pgs 18 - 39 ISNN 1852-2971 Instituto de Cultura Jurídica y Maestría en Sociología Jurídica. FCJ y S. UNLP

parágrafos de la Filosofía del Derechoconcernientes a "violencia y delito" (§ 89-103), si bien es verdad que en el estadio de la moralidad es donde se encuentran las mayores aportaciones (Merle, 2003: 147) (Mayer, 1969: 75).

En el más bajo nivel del movimiento dialéctico de la moralidad se encuentra el Derecho abstracto, 'lo en sí’ (das An-Sich) del espíritu objetivo, la forma embrionaria del desarrollo total, del que se deduce la definición final de Estado como resultado, pero, al mismo tiempo, es asimismo lo 'último' pues tiene como fundamento el sistema total de las formas de la Filosofia del Derecho (Schumacher, 1985: p. 25). En este nivel el Derecho refiere solamente a la relación de los hombres, en tanto personas abstractas y a él pertenece la máxima del $\S$ 36: "sé una persona y respeta a lo demás como personas" (Hegel, 1820: 49), constituyendo el precepto jurídico fundamental de este estadio.

El Derecho abstracto todavía no presupone el concepto de Estado y tampoco apela a la consciencia moral. En él, el individuo se limita a tomar parte del Derecho real, es decir, aquello que corresponde a cada uno en materia de propiedad. Las reglas jurídicas son el resultado del mundo exterior, un mundo atomizado en múltiples posesiones y que se reconoce en su organización patrimonial (Marmasse, 2004:114).

La Filosofía del Derecho se ocupa del delito en primer lugar en el Derecho abstracto. Una comprensión más detallada del concepto del delito como la 'lesión del Derecho como Derecho' presupone, por tanto, no sólo la explicación de este sino,al mismo tiempo, deben ser descritas las primeras formas de desarrollo. Luego, sólo a ellas está contrapuesto el delito en su categoría fundamental (Klesczewski, 1990: 26). Al nivel del Derecho abstracto pertenece también el Derecho en tanto prohibición, y en él el criminal se comporta fácticamente como individuo abstracto. Por otra parte, la respuesta al delito en este nivel es la venganza y no la pena como superación racional de la irracionalidad expresada en el delito.

El segundo nivel del desarrollo dialéctico pertenece a la moralidad. Para Hegel "la transición del Derecho hacia la moralidad acarrea, por lo tanto, la necesidad de la subjetividad, pero al mismo tiempo también la anulación de su aleatoriedad, por lo cual la moralidad se determina en y por sí misma como generalidad” (1817: § 415 observación, 265). Por 'moralidad' Hegel no entiende lo que comúnmente se comprende por 'moral', es decir, el apego

\footnotetext{
${ }^{4}$ En palabras de Hegel“[c]on referencia al acto concreto y a las relaciones morales y éticas, frente a su posterior contenido, el Derecho abstracto sólo constituye una posibilidad; por eso, la prescripción jurídica únicamente es la facultad o licitud. La necesidad de este Derecho, en base de su abstracción, se limita a la prohibición: no perjudicar la personalidad y lo que le atañe. Por ello sólo son prohibiciones jurídicas y la forma afirmativa de las normas jurídicas debe tomar como base a la prohibición de acuerdo a su contenido último" (1820: § 36, 49).
} 
Cordini, N. S. Delito y pena en la teoría de la imputación según Hegel. Derecho y Ciencias Sociales. Noviembre $2019-\mathrm{Abril}_{2020}{ }^{\circ}$ 22. Pgs 18 - 39 ISNN 1852-2971 Instituto de Cultura Jurídica y Maestría en Sociología Jurídica. FCJ y S. UNLP

incondicional (interno) de la personalidad a la norma moral, esto pertenece al ámbito del ‘espíritu absoluto’. Para Hegel la moralidad sólo comprende la forma de la subjetividad, la libertad abstracta del por sí existente individuo en su derecho limitado. ${ }^{5}$ Aquí, el individuo no encuentra sino en sí mismo las reglas de su actuar. Tanto el comportamiento hedonista como la actitud moral de tipo kantiana apuntan a este estadio del pensamiento; en estos dos casos los agentes no se someten a ninguna obligación objetiva, sea ella jurídica (en el sentido del Derecho abstracto) o ética (en el sentido de la eticidad), en la medida que el enamorado del placer como el individuo que actúa por puro deber producen espontáneamente la máxima de su acción: ellos constituyen, el uno y el otro, figuras de la moralidad (Marmasse, 2004: 114). La moralidad es, por lo tanto, el Derecho de la subjetividad y su concepto una voluntad que, "como particular voluntad subjetiva, quiere la generalidad como tal" (Hegel, 1820:§ 103, 93).El actuar moral puede ser incluso inmoral (en el sentido de la eticidad), pero, al mismo tiempo, manifiesta el derecho del sujeto a realizarse en los fines que él mismo ha escogido. La moralidad juega un rol indispensable en la economía general de la Filosofía del Derecho. En efecto, como desarrollo de la subjetividad actuante, ella proporciona las condiciones sistemáticas del advenimiento de la Gesinnung ética específicamente moderna (Marmasse, 2004: 114-115). La importancia de este nivel del desarrollo reside en que es en este estadio donde Hegel desarrolla mayormente su teoría penal, en especial la teoría de la imputación.

Tanto el Derecho abstracto como la moralidad se cancelan en la eticidad, constituyendo éste el verdadero Derecho, con lo cual el derecho verdadero y la eticidad son idénticos, o sea, una unidad trascendental. Sólo en este tercer nivel las exposiciones sobre el Derecho penal son concluidas (Mayer, 1969: 75-76).El Derecho en este tercer estadio del pensamiento no es, por ende, objetivo porque él se corresponda con la convicción general, el sentimiento del Derecho de todo o de la mayoría del pueblo, sino porque él es algo racional general, porque él es una idea con validez general y, como tal, real. Hegel sólo conoce un Derecho, la 'idea del Derecho' (Idee des Rechts) como unidad de su concepto y de su realización (Bubnoff, 1966: 41-42).

Lo que Hegel llama 'Filosofía del Derecho' no es, por tanto, nada distinto a la filosofía del espíritu objetivo, o sea, a la filosofía de todas aquellas determinaciones y relaciones de los

\footnotetext{
${ }^{5}$ Según Hegel, "[1]o moral debe ser tomado en el sentido más amplio, en el que no significa sólo lo bueno. 'Le moral' en la lengua francesa se opone a lo 'psíquico' y significa lo espiritual, lo intelectual en sí. Lo moral tiene aquí, sin embargo, el significado de una determinación de la voluntad, en la medida que está en el interior de la voluntad en general, y se ocupa por eso de la intención y el propósito en sí, como lo moralmente malo" (1830c: $§ 503$ nota, 313).
} 
Cordini, N. S. Delito y pena en la teoría de la imputación según Hegel. Derecho y Ciencias Sociales. Noviembre $2019-\mathrm{Abril}_{2020}{ }^{\circ}$ 22. Pgs 18 - 39 ISNN 1852-2971 Instituto de Cultura Jurídica y Maestría en Sociología Jurídica. FCJ y S. UNLP

hombres entre sí que se distinguen en su libertad, en su existencia como ser racional, que se manifiestan en la elevada naturaleza del hombre: Derecho y Estado, familia y sociedady, finalmente, en el ámbito total de la historia como proceso temporal, en el cual la libertad, el espíritu como en el eterno contra-juego (Wider Spiel) de poderes e ideas que se desarrolla en el eterno desenvolvimiento de sí mismo (Larenz, 1927: 50). En esta unidad dialéctica Hegel pone de manifiesto un punto crucial de su Filosofia del Derecho: el individuo queda referido a la comunidad también en su existencia moral y subordinado a ella. En Hegel comunidad e individuo son así miembros con valor propios de una totalidad cuyos momentos se hallan condicionados entre sí (Welzel, 2005, p. 240).

\section{La teoría de la imputación: la imputación como hecho doloso}

La teoría de la imputación formulada por Hegel puede ser analizada a partir de dos juicios, el primero referido a la imputación del hecho (ilícito), lo que se denomina 'imputación objetiva $^{6} \mathrm{y}$, en un segundo juicio referido a la imputación a la culpabilidad. Resulta necesario aclarar que la división de estos juicios tiene una finalidad explicativa, pues, como veremos más adelante, ambos juicios se refieren el uno al otro, fundiéndose en una unidad.

En primer término, el concepto de 'acción' (Handlung) es sumamente importante para comprender elconcepto hegeliano de imputación, puesto que toda imputación parte de una acción entendida como expresión de una voluntad particular. Hegel en el $\S 113$ de la Filosofia del Derecho sostiene que "la declaración de la voluntad subjetiva o moral es una acción" (1820:98). Esta acción, en la medida que contradice la voluntad general, no es verdaderamente libre, sino expresión de una voluntad particular, o sea, arbitrio; y como tal, pertenece al ámbito de la moralidad. La cuestión de la imputación de la acción en Hegel, esto es, bajo qué supuestos un suceso puede ser atribuido a un sujeto como su acción, es independiente de su valor jurídico o moral. Su respuesta no requiere de ningún juicio de valor, en especial de ninguna consideración de las propiedades individuales del autor para la calificación del hecho, sino solamente un juicio sobre la relación objetiva, lo que llamamos 'imputación objetiva'. Esta sólo nos dice si un suceso (Geschehen) es hecho (Tat) de un sujeto. $^{7}$

\footnotetext{
${ }^{6}$ Nuevamente, no debe confundirse el término aquí utilizado con la 'imputación objetiva del resultado', cuestión que ha sido aclarada en la nota al pie número 1 .

${ }^{7}$ La pregunta sobre si un hecho puede ser subjetivamente imputado a la culpabilidad no está comprendida en el tratamiento de la imputación objetiva sino en el de consciencia de la antijuridicidad.
} 
Cordini, N. S. Delito y pena en la teoría de la imputación según Hegel. Derecho y Ciencias Sociales. Noviembre $2019-\mathrm{Abril}^{2020} \mathrm{~N}^{\circ}$ 22. Pgs 18 - 39 ISNN 1852-2971 Instituto de Cultura Jurídica y Maestría en Sociología Jurídica. FCJ y S. UNLP

La acción subjetiva es analizada por Hegel en la moralidad desde el punto de vista de su finalidad y de su alcance. Es la ampliación progresiva de su alcance la que constituye el hilo conductor del examen sistemático de la acción. Nos preguntamos, entonces, en qué medida ella resulta de un simple impulso o lleva la huella de una deliberación racional.

En la medida en que el sujeto se dirige contra una existencia exterior adversa, su voluntad es limitada, sólo formalmente infinita y, por consiguiente, arbitrio. ${ }^{8}$ La existencia externa se debe presentar como la realización de la voluntad. La 'causalidad de la voluntad' significa, según Hegel, la 'atribuibilidad' (Zurückführbarkeit) de un suceso externo a la voluntad seguida de manera final. En ella se distinguen dos momentos: elprimero, el del conocimiento, o sea la 'previsión' (Voraussicht) del curso causal; el segundo, el de la 'causalidad de la voluntad', o sea, la capacidad fundada en el conocimiento obtenido del curso causal para dar la dirección deseada. Ambos producen el concepto de 'artífice' (Urheber) o, como Kant acertadamente llama: la 'causa libera' (1797: 227). Artífice sólo deviene el hombre, en la medida que su finalidad se arraiga en la libertad de su voluntad. El hecho y su imputación encuentran su límite en el alcance de la 'fuerza de voluntad' (Willensmacht). Sólo aquellas consecuencias de la inmediata actuación pueden ser imputadas como acción, o sea, como hecho que el actor ha presupuesto, del cual él era consciente y de él fueron perseguidos. ${ }^{9}$

En este punto ingresa en el sistema hegeliano el concepto de 'dolo' (Vorsatz) como criterio delimitador de aquello que puede ser imputado como acción. ${ }^{10}$ La causación de la existencia externa debe ser el dolo de la voluntad subjetiva, debe coincidir con la voluntad, que internamente existe como dolo (Bubnoff, 1966: 43). Según Hegel, “el dolo concierne sólo a

\footnotetext{
${ }^{8}$ En términos de Hegel:“el punto de vista de la diferencia, la finitud y lo fenoménico de la voluntad” (1820: $\S$ 108, 96).

${ }^{9}$ Más allá que Hans Welzel en el Vorwort de Naturalismusund Wertphilosophieim Strafrecht (1935: VIII-IX) coloca a su teoría ámbito de lo permanente, sin relación con el tiempo, rechazando todo retorno a un sistema filosófico anterior, en especial al hegeliano. Resulta, sin embargo, interesante la comparación que hace Bubnoff (1966: 51) entre el concepto de acción final seguido por Hegel y el propio de Welzel. Esta relación se advierte especialmente en la posición central que adquiere la libre personalidad moral en el ilícito. El ilícito no puede, según Hegel, ser comprendido sólo de manera naturalista, sino teleológicamente. El centro de gravedad del concepto de ilícito yace, por tanto, en lado personalístico (perosnalistische Seite). El ilícito presupone una personalidad libre como artífice (Urheber). En la teoría de Hegelya resuena la distinción entre desvalor de acción y desvalor de resultado (Handlungs- und Erfolgsunwert), tal como la encontramos en la teoría de la acción final de Welzel. Además, según Hegel, la acción es en la consideración del ilícito sólo como obra (Werk) de un determinado autor que lo dota significado a través de la fijación de un fin (Zielsetzung). El contenido de la voluntad caracteriza el hecho objetivo. La mera causación de un resultado, o sea la lesión de un bien jurídico, por el contrario, no agota el ilícito. Al igual que Hegel, Welzel elabora su concepto de acción final centrado en el desvalor de la acción en el cual el concepto de dolo cumple la función de filtro.

${ }^{10}$ La teoría de la acción final de Welzelse reconecta con la teoría de la acción final de Hegel en el concepto de dolo. El actuar doloso no es ningún mero naturalismo, sino la concepción autoconsciente de la realidad (Köhler, 1999: 70). En sentido similar se pronuncia Lesch (1999a: 101).
} 
Cordini, N. S. Delito y pena en la teoría de la imputación según Hegel. Derecho y Ciencias Sociales. Noviembre $2019-\mathrm{Abril}_{2020}{ }^{\circ}$ 22. Pgs 18 - 39 ISNN 1852-2971 Instituto de Cultura Jurídica y Maestría en Sociología Jurídica. FCJ y S. UNLP

lo formal, que es tanto la voluntad externa como la interior en mí” (1820: §114 adición, 314). El dolo, en tanto propósito de la acción, no sólo incluye las consecuencias expresamente tenidas como propósito, sino también aquellas consecuencias que se prevén al actuar, incluso si el autor no las desea (Wood, 1990: 140). Hegel incluso considera como dolo aquellas consecuencias que el autor no puede prever si ellas pertenecen a la naturaleza de la acción en sí misma (1820: $§ 118$ adición,315). ${ }^{11}$

Según Hegel, la voluntad en tanto arbitrio es finita y puede que no concuerde con la existencia exterior. Si bien es verdad que el hombre es el 'amo' (Herr) del curso causal, en la medida en que él es capaz de dominarlo, lo es sólo hasta cierto grado. Puede suceder que el hombre, en su intervención en el suceso, también pueda producir involuntariamente modificaciones que él quizás no pudo presuponer: en otros términos, todo dolo puede tropezar con circunstancias no conocidas del sujeto $(1820$ : $\$ 117,100)$ o, incluso, combinarse a sucesos imprevistos $(1820: \S 118,101)$ que, los unos como los otros, impiden la realización de la finalidad o arrastran efectos perversos.

El riesgo de fracaso de la acción no se encuentra en la ceguera de un agente que sería incapaz de discernir un medio en sí eficiente, sino en el conflicto inevitable entre dos fuentes posibles de eventos observados: el agente, por una parte, y las circunstancias externas, por otra. La voluntad del sujeto interviene en una objetividad natural y espiritual que permanece caracterizada por una procesualidad propia y, en consecuencia, recíproca a la finalidad considerada, porque en la moralidad todavía no hay 'supresión' (Aufhebung) ${ }^{12}$ del mundo por el concepto sino simplemente negación abstracta (a la inversa, por ejemplo, de lo que se observa en la Sittlichkeit). La competencia es inevitable entre el sujeto y lo objetivamente dado, que constituyen, el uno al otro, el origen de todo posible efecto (Marmasse, 2004: 120121). Por tanto, aquello que se considera contingente o accidental no puede ser imputado a la acción. Lo accidental es, en la acción, todo aquello que era ajeno a la voluntad y por tanto no era sabido (Hegel, 1820: § 117, 101).Imputable, por lo tanto, es aquello que es sólo 'lo suyo’ (das Seigine) de la voluntad, es decir lo que es tenido en cuenta en la previsión de la voluntad. La finalidad es el 'alma de la acción' (Seele der Handlung). Decisiva no es por tanto la mera causalidad sino la dirección final de la acción (Hardwig, 1957: 56).

\footnotetext{
${ }^{11}$ La 'naturaleza' de una cosa es, según Hegel, lo que captamos de una reflexión racional sobre ella y de las conexiones con otras cosas (1830a: $\S 23$, p. 80).

${ }^{12}$ El sustantivo 'Aufhebung' derivado del verbo 'aufheben' es una palabra alemana con varios significados contradictorios entre ellos: 'levantar', 'suprimir', o 'sublimar'. El término también ha sido utilizado como 'abolir', 'preservar' o 'trascender'. En la filosofía, dichos conceptos son utilizados por Hegel para explicar los que sucede cuando una tesis y una antítesis interactúan.
} 
Cordini, N. S. Delito y pena en la teoría de la imputación según Hegel. Derecho y Ciencias Sociales. Noviembre $2019-\mathrm{Abril}_{2020}{ }^{\circ}$ 22. Pgs 18 - 39 ISNN 1852-2971 Instituto de Cultura Jurídica y Maestría en Sociología Jurídica. FCJ y S. UNLP

Según Hegel, es el derecho de la voluntad, que sólo puede imputar las consecuencias que son el fin de la acción $(1820, \S 118,101)$, porque sólo ellas son queridas, no así las consecuencias lejanas, extrañas. A esta finalidad que representa la esencia del determinado hecho, que otorga a la acción el contenido general, la denomina Hegel 'propósito' (Absicht).${ }^{13}$ De ello se sigue que el sistema hegeliano sólo prevé la imputación dolosa de la acción. A los efectos del dolo, es suficiente que el autor conozca la naturaleza general del hecho. Es decir, para que un efecto le sea imputable, se requiere que el agente conozca el hecho por su significación objetiva y sus implicaciones. Con la acción como totalidad se le puede imputar las consecuencias particulares, necesarias. Acerca de la posibilidad de fundamentar la imputación de las acciones imprudentes conforme al sistema hegeliano, será tratado en un apartado especial.

\section{La imputación como hecho antijurídico}

La acción es para Hegel la realización total de la voluntad. La misma comprende tanto el actuar inmediato del sujeto como también las consecuencias como suceso independiente. En la medida en que las consecuencias se encuentren con la acción en una relación teleológica como suceso dominado por la voluntad, en la medida que el autor es servil a una finalidad, forman parte de la acción. Pero sólo la acción está sujeta a un juicio jurídico. Por consiguiente, sólo ella puede ser objetivamente antijurídica. Antijurídica es entonces la acción que alcanza a las consecuencias en la medida en que ambas estén unidas mediante una relación teleológica.

La imputación objetiva en Hegel comprende la atribución de un 'suceso' (Geschehen) a un sujeto como su 'hecho' (Tat), es decir, como su 'acción' (Handlung). Este juicio no comprende ningún tipo de valoración, no tiene en cuenta las capacidades personales del autor, aunque resulta necesario destacar que la valoración jurídica del hecho, es decir su valoración como 'ilícito'(Unrecht), ya está aquí presupuesta o, mejor dicho, la antijuridicidad objetiva presupone una imputación objetiva. Por tanto, la imputación objetiva abarca la atribución de un suceso como acción antijurídica, es decir, la imputación objetiva es el juicio mediante el cual un suceso es considerado como acción antijurídica de un sujeto. Lo que queda fuera de tratamiento en este nivel de análisis es la problemática de la

13 “... pero la verdad de lo singular es lo universal y la determinación de la acción es por sí, no un contenido aislado de la individualidad externa, sino un contenido universal, que envuelve en sí múltiple conexión. El propósito, en cuanto procede de un ser pensante, no encierra meramente la individualidad, sino esencialmente el aspecto universal, esto es, la intención" (Hegel, 1820, § 119, 102). 
Cordini, N. S. Delito y pena en la teoría de la imputación según Hegel. Derecho y Ciencias Sociales. Noviembre $2019-\mathrm{Abril}_{2020}{ }^{\circ}$ 22. Pgs 18 - 39 ISNN 1852-2971 Instituto de Cultura Jurídica y Maestría en Sociología Jurídica. FCJ y S. UNLP

‘consciencia del ilícito' (Unrechtsbewusstsein), que es analizada en la culpabilidad (imputación subjetiva).

\section{Imputación objetiva y omisión}

A partir del concepto de acción final utilizado por Hegel se puede deducir que el mismo abarca también al actuar omisivo, entendiéndolo no como una relación real entre un acontecimiento y un sujeto, sino como una relación imaginada (Larenz, 1927: 85). En este contexto, omisión es la 'no ejecución' (die Nichtvornahme) de una acción presupuesta, exigida como posible. En el concepto hegeliano de omisión yace, por tanto, una relación de la voluntad con una posible acción presupuesta; puesto que la posibilidad de una acción omisiva se funda en la libertad, una posibilidad de la voluntad es, por consiguiente, la omisión imputable (Bubnoff, 1966: 46-47).

El concepto de la libertad le permite a Hegel unificar tanto el actuar comisivo como el omisivo, dado que en su modelo de comprensión la relación causal es relegada a un segundo plano, siendo la 'causalidad de la voluntad' (Willenskausalität), o sea, el 'poder de la voluntad' (Macht des Willens) de dominar adecuadamente el curso causal, el criterio decisivo tanto para la imputación del actuar comisivo como de las omisiones. Hegel en el $\S$ 116 de la Filosofía del Derecho, ${ }^{14}$ no estipula la responsabilidad por el hecho cometido de propia mano, sino que regula la responsabilidad por la voluntad omisiva, esto es, "la responsabilidad qua dominio sobre un ámbito de organización y en la infracción de un deber de diligencia" (Lesch,1999a:131).De esta manera, la medida de la mayor o menor responsabilidad se rige entonces por la intensidad de la relación de domino, esto es, según la medida de la atención debida o, en otros términos, del cuidado necesario (Lesch, 1999a: 132).

\section{5. ¿Es posible fundamentar una teoría hegeliana del delito imprudente?}

Hegel, a lo largo de su obra, sólo se abocó de manera expresa a la imputación del hecho doloso, dejando fuera de tratamiento las acciones imprudentes. Una cuestión discutida por la

\footnotetext{
${ }^{14}$ En términos de Hegel: "No es, en verdad, un acto propio mío, si las cosas -de las cuales soy propietario y que como externas están y obran conjuntamente con gran frecuencia (como puede suceder conmigo mismo en cuanto cuerpo mecánico o ser viviente)-, causan en esa forma perjuicio a los otros. En eso, yo soy más o menos responsable, porque, en general, aquellas cosas son mías; pero, sin embargo, según su propia naturaleza, están más o menos sujetas a mi dominio y vigilancia” $(1820: \S 116,100)$.
} 
Cordini, N. S. Delito y pena en la teoría de la imputación según Hegel. Derecho y Ciencias Sociales. Noviembre $2019-\mathrm{Abril}^{2020} \mathrm{~N}^{\circ}$ 22. Pgs 18 - 39 ISNN 1852-2971 Instituto de Cultura Jurídica y Maestría en Sociología Jurídica. FCJ y S. UNLP

doctrina es la de la posibilidad de fundamentar, a partir de las afirmaciones hechas por Hegel, la responsabilidad por la conducta imprudente. Tradicionalmente, el $\S 116$ de la Filosofia del Derecho es interpretado no como casos de imprudencia, sino como la regla civil de responsabilidad por el riesgo (Jermann, 1987: 105), (Hösle, 1988: 513), (Bubnoff, 1966: 45), negando la posibilidad de fundamentar, a partir de la teoría hegeliana, la imputación de hechos imprudentes. Entre aquellos que se muestran favorables a un posible esbozo del delito imprudente, a partir de una interpretación del parágrafo antes señalado, se encuentran Radbruch (1903:101, nota al pie no 1) Hardwig (1957: 57-58), Lesch (1999a: 135) y Larenz (1927: 52-53).

Larenz reconoce que, si bien Hegel sólo trató la imputación del hecho doloso, sin embargo, a través de la interpretación de la Filosofía del Derecho es posible fundamentar una imputación de las consecuencias del hecho imprudente. El $\S 116$ no trata la imputación de una acción del sujeto y su resultado, y la relación entre la voluntad y el resultado no es una causalidad. No se trata indudablemente de ningún actuar doloso, pero ellos pueden y deben ser imputados, sin embargo, como acciones imprudentes o, al menos, objetivamente como hecho. Según este autor, Hegel relaciona la responsabilidad del $\S 116$ con un 'deber de cuidado', con ello no puede referirse a ninguna responsabilidad por el resultado, sino sólo a una responsabilidad por culpa $\mathrm{y}$, por consiguiente, esa responsabilidad no puede ser calificada como responsabilidad por riesgo (1927: 53). ${ }^{15}$ Hegel ha comparado mutuamente con gran persistencia lo propio (das Eigene) y lo accidental (das Zufällige) y ha reconocido que sólo puede ser imputado como propio, lo que está en relación con la libertad. Al respecto Hegel afirma:" pero yo solo soy, lo que está en relación a mi voluntad, y el hecho es solo culpabilidad de mi voluntad, siempre que, por lo tanto, lo conozca" (1820: $§ 117$ adición, 315). Según Larenz, en estas frases Hegel comete el error de ignorar que la voluntad es el propio hecho de la libertad que, a mí, por tanto, también, en este sentido, me puede ser imputado 'lo no conocido' (das Nicht-Gewusst), si lo no conocido no era para mí accidental, sino obra de mi libertad: si según el conocimiento de las circunstancias era para mí un conocimiento posible. Donde esta posibilidad de conocimiento y no ya donde el propio conocimiento termina, termina también la imputación del hecho y comienza el ámbito de los meros sucesos causales (Larenz, 1927: 53).

\footnotetext{
${ }^{15}$ Lesch también afirma que el $\S 116$ refiere al delito imprudente, pero a diferencia de Larenz, considera que Hegel se ha adelantado a su época al concebir a la imprudencia no como una acción sino como una omisión (1999a: 132; 135), como cansos en los que existe una posición de garantía en virtud de una competencia por organización en los que, aunque el autor ya no está actuando causalmente, su círculo de organización ha tenido efectos externos (Jakobs, 1991: 213).
} 
Cordini, N. S. Delito y pena en la teoría de la imputación según Hegel. Derecho y Ciencias Sociales. Noviembre 2019 - Abril 2020 N ${ }^{\circ}$ 22. Pgs 18 - 39 ISNN 1852-2971 Instituto de Cultura Jurídica y Maestría en Sociología Jurídica. FCJ y S. UNLP

\section{La imputación subjetiva: la capacidad de culpabilidad}

Como hemos visto con anterioridad, la imputación objetiva en Hegel no requiere ningún juicio de valor, sino sólo constituye un juicio sobre la relación objetiva, es decir, sólo nos dice si un suceso (Geschehen) es hecho (Tat) de un sujeto. Hegel distingue la imputación de una acción según el conocimiento del autor de su 'valor' (Wert) o 'desvalor' (Unwert) “como fin que llega a la objetividad externa" (1820: $\S 132,110)$.En el tratamiento de la imputación objetiva, el valor o desvalor de la acción queda fuera de tratamiento: la valoración jurídica ya está aquí presupuesta. Por tanto, hay que distinguir entre la valoración de la acción en tanto acción antijurídica y la cuestión de la imputación de la acción valorada como ilícita (antijurídica) en vista del conocimiento existente de su desvalor por el autor. En el ámbito de esta segunda problemática trata Hegel la cuestión de la 'consciencia del ilícito' (Unrechtsbewusstsein) o, con otras palabras, la cuestión de la culpabilidad (Bubnoff, 1966: 47-48).La reflexión sobre este momento subjetivo de la imputación conduce a la consideración de la singularidad del sujeto, en términos de Hegel, el "poder y la fuerza de la autoconsciencia" (Hegel, 1820: § 120 adición,103-104), la“imputabilidad subjetiva’ (subjektive Zurechnungsfähigkeit) (Larenz, 1927: 58).

La empírica real constitución del sujeto sólo es significativa en el marco del establecimiento de la capacidad de imputación. Una vez establecida esta capacidad, la imputación se dirige sólo a una medida objetiva generalizante (Hegel, 1820: § 120 adición,103-104) es decir, se orienta a una expectativa normativa, esto es, no al sujeto tal y como psicológicamente está dispuesto, sino tal y como él debería estar dispuesto, a saber, como persona racional, como voluntad libre, que tiene como contenido lo objetivo-general. La culpa subjetiva de la voluntad particular en la teoría de Hegel se ve concretada sólo en la capacidad de culpabilidad (Lesch, 1999a: 128-129),

La noción de culpabilidad, estrictamente hablando, no tiene entonces un carácter pecaminoso de la voluntad, sino que está referida a su carácter deliberado. Para Hegel, la culpabilidad, no está originariamente ligada a la falta, sino más bien al hacerse cargo de un acto por su sujeto. La 'responsabilidad' (Verantwortung) supone así la identidad de un individuo y su acción (Marmasse, 2004: 127). 'Responsabilidad' significa, según Hegel, deber hacerse cargo del propio hecho (responsabilidad por las consecuencias), ella tiene a la imputación como presupuesto. Imputación y culpabilidad no coinciden. En la fundamentación de la culpabilidad es, junto al juicio de imputación, un juicio normativo sobre el valor externo del hecho en cuanto necesario reproche subjetivo de culpabilidad. 
Cordini, N. S. Delito y pena en la teoría de la imputación según Hegel. Derecho y Ciencias Sociales. Noviembre 2019 - Abril 2020 N ${ }^{\circ}$

22. Pgs 18 - 39 ISNN 1852-2971 Instituto de Cultura Jurídica y Maestría en Sociología Jurídica. FCJ y S. UNLP

La culpabilidad presupone únicamente imputación subjetiva, que hace referencia a la interna determinación de la voluntad del sujeto. El juicio normativo, o sea, el juicio sobre la antijuridicidad objetiva, requiere, por el contrario, una imputación objetiva. Si bien ambos juicios son diversos, se encuentran estrechamente relacionados. La imputación objetiva del hecho encuentra su complemento a través de la imputación subjetiva, que toma como punto de partida las capacidades, la comprensión y el propósito individual del autor (Larenz, 1927: 58), pero, al mismo tiempo, la imputación subjetiva encuentra, del mismo modo, su limitación en el sentido objetivo del hecho; en términos de Hegel, "un propósito moral (...) no puede justificar una acción ilícita" (1820: § 126, 107). De este modo, la contradicción entre objetividad y subjetividad es superada a través de la trascendencia de ambos momentos en una unidad. Tanto la relación teleológica objetiva del hecho, es decir, la imputación objetiva, como la finalidad subjetiva del autor, se convierten en objeto de valoración jurídica y moral.

\section{Capacidad de acción e imputabilidad}

Dentro de la problemática de la consciencia del ilícito es válido preguntarse si, conforme al esquema de análisis de Hegel, a un inimputable puede serle objetivamente imputado una acción ilícita. Respecto de esta cuestión caben dos posibilidades.

La primera de ellas es considerar que la imputación objetiva y la antijuridicidad objetiva representan un juicio sobre el hecho, así como sobre el lado objetivo de la voluntad, entonces la imputación objetiva sólo presupone que el suceso está relacionado a un sujeto en tanto persona, pero no que ese hecho corresponda a la verdadera voluntad del autor, que a éste también, según su comprensión individual y su propósito, puede serle subjetivamente imputado (Larenz, 1927: 58). Conforme a esta interpretación, la personalidad del inimputable, sería negada en términos de Hegel, pero no destruida. En tanto persona es, no obstante, titular de derechos y deberes y su conducta puede ser imputada objetivamente, pero no subjetivamente.

La segunda postura, por el contrario, se pronuncia identificando 'capacidad de acción' (Handlungsfähigkeit) e imputabilidad o ‘capacidad de imputación’ (Zurechnungsfähigkeit); para ello se toma como base el $\S 120$ de la Filosofía del Derecho conforme al cual la acción 
Cordini, N. S. Delito y pena en la teoría de la imputación según Hegel. Derecho y Ciencias Sociales. Noviembre $2019-\mathrm{Abril}_{2020}{ }^{\circ}$ 22. Pgs 18 - 39 ISNN 1852-2971 Instituto de Cultura Jurídica y Maestría en Sociología Jurídica. FCJ y S. UNLP

presupone imputabilidad. ${ }^{16}$ La voluntad, sin embargo, sólo alcanza la capacidad de manipularse como libre, cuando el hombre comprende conscientemente la voluntad separada de los impulsos. El hecho del inimputable no puede, por tanto, ser contemplado como acción en sentido jurídico. La inimputabilidad excluye la capacidad jurídico-penal de acción. La capacidad de culpabilidad y la capacidad de acción son, en este sentido, idénticas (Bubnoff, 1966: 49).

En el sistema hegeliano, la distinción entre objetividad y subjetividad no es tajante, sino que ambas se sintetizan en una unidad. Esto conlleva a que, en última instancia, la imputación al hecho se apoye sobre la culpabilidad: la acción es siempre 'acción culpable'. ${ }^{17}$ En caso de que ésta falte, ya no cabría la imputación como hecho. Así, el suceso originado por el sujeto sería una mera contingencia, expresión de una persona sólo en términos formales, pues una vez establecida la imputabilidad, la imputación se orienta sólo a una medida objetiva general, a una expectativa normativa, esto es no al sujeto tal y como está dispuesto psicológicamente, sino al sujeto tal y como debería estar dispuesto, es decir, en tanto persona racional, como voluntad libre, que tiene como contenido lo objetivo-general (Lesch, 1999a: 128-129). ${ }^{18}$

La natural capacidad interior del sujeto, su empírica real constitución es significativa solamente en el marco de la previa clarificación de la capacidad de imputación, pero no lo es en el marco de la imputación propiamente moral (Flechtheim, 1975: 87-88), de manera tal que la culpa subjetiva de la voluntad particular en el sistema hegeliano se ve concretada sólo en la capacidad de voluntad esto es, en el "honor de ser un ser pensante, de ser una voluntad" (Hegel, 1820: $\S 120,103-104)$, por lo tanto, en el concepto jurídico de la capacidad de voluntad (Jermann, 1987: 107) (Lesch, 1999a: 129). La sección de la moralidad de Hegel tiene por corolario que no se puede reprochar al niño, al imbécil o al

\footnotetext{
${ }^{16}$ Así, Hegel en el $§ 120$ declara: “[p]ero como las acciones según su existencia externa, encierran en sí la accidentalidad de efectos, así también la existencia subjetiva contiene la indeterminación, la cual se refiere al poder y a la fuerza de la autoconciencia y del juicio -indeterminación que, sin embargo, puede considerarse sólo respecto a la imbecilidad, a la locura y demás cosas semejantes, así como a la edad infantil -; porque sólo tales situaciones decididas anulan el carácter del pensamiento y de la libertad volitiva y permiten no considerar el agente de acuerdo al honor de ser pensamiento y voluntad" (1820: 103-104).

${ }^{17}$ A este modelo se acerca jakobs al postularun tipo total de imputación (Gesamtzurechnungstatbestad) que abarcaría todos los presupuestos de la acción culpable (2012: 24).Para Jakobs la acción y la imputación - y ésta a su vez presupone la imputación del injusto - son lo mismo. El comportamiento, en cuanto suceso psíquicofísico, debe ser objetivamente imputable, evitable y culpable" (1997: 124).Establece a la culpabilidad como presupuesto de la imputación. Además, considera que un concepto de acción acorde con la función del Derecho penal debe ser ampliado hasta la culpabilidad. Acción es convertirse en culpable. Acción es aquel comportamiento que hace necesaria la imposición de una pena, en términos de Jakobs, "acción es convertirse en competente por una lesión de la vigencia de la norma" (1997: 124).

${ }^{18}$ En términos de Hegel: "[m]ientras pienso (como racional) conozco y quiero, quiero las condiciones generales, de lo racional en y para sí, de lo sustancial. Con ello vemos una unión, que es en sí, entre el lado objetivo (el concepto) y el subjetivo". (Hegel, 1986a: 68).
} 
Cordini, N. S. Delito y pena en la teoría de la imputación según Hegel. Derecho y Ciencias Sociales. Noviembre 2019 - Abril 2020 N ${ }^{\circ}$ 22. Pgs 18 - 39 ISNN 1852-2971 Instituto de Cultura Jurídica y Maestría en Sociología Jurídica. FCJ y S. UNLP

loco, como tampoco al animal, ${ }^{19}$ de cometer acciones de consecuencias desastrosas. Inversamente, tratar a alguien como culpable, es de cierta manera honrarlo en tanto persona, reconociéndole la posesión de razón (Marmasse, 2004: 123).

\section{El delito como negación del Derecho}

El sujeto, a través de su acción, contrapone a la voluntad general en sí existente su (arbitraria) voluntad particular, produciendo la lesión del Derecho. El ilícito es, para Hegel, una negación arbitraria del Derecho; es una negación arbitraria porque constituye la existencia de una voluntad particular y, en esa forma de Derecho, está contrapuesta a la voluntad general racional. El delito una autorrevocación de la libertad y con ello es lo no racional, lo que una sustancial voluntad libre per se no puede tener como contenido (Schild, 1981: 457). El sujeto en su individualidad niega la eticidad, es decir, su naturaleza objetivamente determinada. El autor pone en duda la norma a través de la pretensión de generalidad de su particularidad, esto es como pauta de conducta válida. Sin embargo, el ilícito, en tanto existencia objetiva externa, es irreal.

El ilícito es expresión de la voluntad subjetiva, de una voluntad particular y supone la voluntad particular del delincuente frente a la voluntad general; es la lesión del Derecho como Derecho, esto es, en la voluntad particular del delincuente, que afirma el ilícito (Lesch, 1999a: 81-82; 1999b: 13). Así Hegel en el § 97 de la Filosofía del Derecho afirma:

"la vulneración del Derecho como tal es, ciertamente, una existencia positiva, exterior, que es en sí nula. La manifestación es la anulación de la existencia de aquella vulneración; es la realidad del Derecho como su necesidad que se concilia consigo misma mediante la negación de su vulneración" (1820: 87).

El delito es incapaz de derogar el Derecho como Derecho, esto es, en su naturaleza absolutamente inderogable. En Hegel, la nulidad del delito se manifiesta en su destrucción, en su 'exterminabilidad'. Entonces, el Derecho como negación de esa negación (ilícito) encuentra su realidad ya en el aniquilamiento del ilícito nulo.

El criminal no sólo lesiona a través del hecho al Derecho, sino que al mismo tiempo se lesiona a sí mismo como ser racional. Su hecho es la negación del espíritu. Lo único racional en el hecho del autor es que el autor, en principio, es un ser racional (Seelmann, 2007: 636). El sujeto, en tanto criminal, es sólo formalmente sujeto racional, sólo formalmente persona, puesto que, en tanto negación de la voluntad general, que por sí sola representa el libre

\footnotetext{
${ }^{19}$ Según Hegel, “sólo el animal (...) es realmente no culpable” (Hegel, 1986a: 51).
} 
Cordini, N. S. Delito y pena en la teoría de la imputación según Hegel. Derecho y Ciencias Sociales. Noviembre $2019-\mathrm{Abril}_{2020}{ }^{\circ}$ 22. Pgs 18 - 39 ISNN 1852-2971 Instituto de Cultura Jurídica y Maestría en Sociología Jurídica. FCJ y S. UNLP

albedrio, el delito representa una autocancelación de la libertad y, con ello, lo absolutamente irracional, lo cual es sustancial dado que la voluntad verdaderamente libre per se no puede hacer de contenido.

\section{La pena como reafirmación del Derecho}

El último de los conceptos del sistema penal hegeliano que debemos desarrollar para comprender su teoría de la imputación es el de pena, puesto que la misma se halla en una relación funcional con las categorías antes analizadas.

La teoría hegeliana de la pena es caracterizada a través de una relación recíproca, de índole funcional, entre delito y pena (Lesch, 1999a: 79-80). Ser imputable es, según Hegel, ser persona racional. La personalidad va unida al ejercicio actual de la racionalidad. Quien reclama para sí un ámbito de libertad (un círculo de organización), asume con ello la responsabilidad por las consecuencias que traiga consigo ese ámbito que se administra de manera propia, puesto que libertad sin responsabilidad no es realmente verdadera libertad personal, sino mero arbitrio subjetivo (Lesch, 1999b: 16).

Dado que el delito representa la voluntad particular del delincuente, pretendiendo que la voluntad particular tenga vigencia en su particularidad, el modo de superar esta particularidad se da a través de la pena. Ésta no es una mera reacción, aprehensible empíricamente como un mal que viene a negar el mal ocasionado por el delito. El delito debe ser superado dialécticamente, por ello la pena, en tanto'negación de la negación del Derecho, ${ }^{20}$ reintegra el carácter racional al autor confirmando, al mismo tiempo, la norma. La 'negación de la negación' no debe ser comprendida como la negación de un opuesto, como si (A) fuese la negación de $(\neg \mathrm{A})$, o sea $(\neg \neg \mathrm{A})$. La negación de la negación es la ‘supresión' (Aufhebung) de la negación, o sea la supresión de la ‘coacción’ (Zwang). Ella no es $(\neg \neg \mathrm{A})$, sino (A). La 'negación de la negación' es, entonces, (A), que tiene validez a través de la negación: la pena es la negación que debe finalizarabsolutamente la negación (Merle, 2003: 159).

\footnotetext{
${ }^{20 ، " L a}$ vulneración con la cual es afectada la voluntad que es en sí (es decir, respecto a la voluntad de aquel que viola, así como a la del vulnerado y de los demás), no tiene existencia positiva en esa voluntad, que como tal es en sí, como tampoco en el simple producto. Por sí, esta voluntad que es en sí (Derecho, Ley en sí), es, más bien, lo exteriormente no existente y, a este respecto, inviolable. La vulneración, para la voluntad particular del ofendido y de los demás, es sólo algo negativo. La existencia positiva de la vulneración es sólo en cuanto voluntad individual del delincuente. La vulneración de esta voluntad en cuanto existente es la anulación del delito, que de otro modo sería válido; es el restablecimiento del Derecho" (Hegel, § 99, 88).
} 
Cordini, N. S. Delito y pena en la teoría de la imputación según Hegel. Derecho y Ciencias Sociales. Noviembre $2019-\mathrm{Abril}^{2020} \mathrm{~N}^{\circ}$ 22. Pgs 18 - 39 ISNN 1852-2971 Instituto de Cultura Jurídica y Maestría en Sociología Jurídica. FCJ y S. UNLP

La pena, en tanto respuesta 'racional', no se produce en el nivel del derecho abstracto, sino en el de la eticidad. La respuesta que se da en el primer estadio del desarrollo dialéctico es, en cambio, la 'venganza' (Rache). ${ }^{21}$ La superación del delito a través de la pena, en lugar de la venganza privada, no se asienta, en que la venganza privada acarree la parcialidad,puesto que el mismo Hegel reconoce que en la venganza justa, según su contenido, el vengador puede actuar legítimamente (1820: §102, 92-93). El Derecho, que como Derecho se restaura, en caso de venganza es la personalidad de la víctima, en caso de la pena, por el contrario, la validez del Derecho. El delito y la penano se asientan, por consiguiente, en el plano del ensamble de dos males, sino que lo hacen en el plano de la razón: el delito es lo irracional y la pena reestablece lo racional (Lesch, 1995: 920). En términos de Hegel, "en esta discusión lo que únicamente interesa es que el delito debe negarse no como la producción de un mal, sino como la vulneración del Derecho como Derecho” (1820: §99, 89).A la venganza privada, subjetiva y accidental, propia del derecho abstracto, Hegel le opone la justicia penal; ella no sólo reconoce la personalidad del criminal, sino también de todos miembros de la comunidad jurídica. ${ }^{22}$ Sólo cuando el delito y la pena se interrelacionan conceptualmente, cuando son entendidas a modo de 'discurso y réplica', y de esta manera se sitúan en un mismo contexto interno y funcional, se puede hablar de una pena verdadera, en sí y para sí justa, esto es, idéntica al Derecho como objetivamente racional (Hegel, 1820: $\S 100,89-90)$. El delito debe ser superado no como creación de un 'mal externo' sino como lesión del Derecho en tanto que Derecho y, por, ello, en la voluntad particular del delincuente que afirma el ilícito (Lesch, 2001: 22). Como sostiene de Hegel:

"La vulneración que afecta al delincuente no es sólo justa en sí - como justa es, a la vez, su voluntad, que es en sí y la existencia de su libertad, su Derecho -, sino que también es un Derecho impuesto en el delincuente mismo, esto es, en su voluntad existente, en su acción. Porque en su acción, como acción de un ente racional, está implícito un universal: el que por medio de ella esté instituida una ley, a la que el delincuente ha reconocido por sí, y bajo la cual

\footnotetext{
${ }^{21}$ En términos de Hegel: "la superación del delito en la esfera del Derecho abstracto es principalmente venganza, justa, según el contenido en cuanto es represalia (...) La venganza, por el hecho de que es una acción positiva de una voluntad particular, viene a ser una nueva vulneración, incorporándose como tal contradicción en el progreso al infinito y pasa en herencia, de generación en generación, ilimitadamente"( 1820 , $\S 102,92)$.

${ }^{22}$ De este modo, Hegel sostiene que:“el Derecho, en presencia del delito, bajo la forma de la venganza (§ 102), sólo es derecho en sí, no es la forma de lo jurídico, es decir, no es justo en su existencia. En lugar de ser vulnerada la parte, es lesionado lo universal, que el juicio tiene realidad propia y se encarga de la persecución y castigo del delito, que, en consecuencia, cesa de ser sólo el cambio subjetivo y contingente por medio de una venganza y se transforma en la verdadera conciliación del derecho consigo mismo, en la pena; esto es, en la consideración del Derecho consigo mismo, en la pena; esto es, en la consideración objetiva como conciliación de la ley que se restablece a sí misma mediante la negación del delito y, por lo tanto, realizándose como válida; $\mathrm{y}$, en consideración subjetiva del delincuente, como conciliación de su ley por él conocida y válidapara él, y como protección de la misma que al efectuar por sí mismo, le proporciona al mismo tiempo y por este motivo la satisfacción de la justicia y sólo la realidad de su Yo. (1820: § 220,p. 178).
} 
Cordini, N. S. Delito y pena en la teoría de la imputación según Hegel. Derecho y Ciencias Sociales. Noviembre $2019-\mathrm{Abril}_{2020}{ }^{\circ}$ 22. Pgs 18 - 39 ISNN 1852-2971 Instituto de Cultura Jurídica y Maestría en Sociología Jurídica. FCJ y S. UNLP

puede ser asumido, como bajo su Derecho" (1820: $§ 100,89)$.

El ilícito no sólo implica la negación de la voluntad general a través de la voluntad particular del delincuente, sino que, al mismo tiempo, el sujeto se lesiona a sí mismo en su carácter de ser racional. La pena, a su vez, reintegra al sujeto delincuente su racionalidad, ya que ésta mantiene la personalidad del sujeto delincuente. En términos de Hegel: "este honor no llega a él si el concepto y la norma de su pena no se toman de su mismo acto y si es considerado el delincuente como un animal dañino al que habría que hacer inofensivo, o a los fines de la intimidación y de la corrección”(1820: §100, 90).El delincuente es considerado persona libre y responsable, a la que se le reconoce el derecho de configurar el mundo según su voluntad, acarreando, al mismo tiempo, responsabilidad por las consecuencias. ${ }^{23}$

\section{Conclusiones}

Conforme a la postura de Hegel, las teorías de la imputación y de la pena se basan en el mismo principio que no es otro que el sinalagma entre libertad de organización y responsabilidad por las consecuencias, esto es, en la responsabilidad de una persona formal racional.Abordar los conceptos: imputación, culpabilidad y pena de manera aislada, conllevan una visión parcial y sesgada de su sistema de imputación.

En el sistema hegeliano existe una interdependencia entre 'imputación objetiva' e ‘imputación subjetiva', dado que la imputación presupone capacidad de imputación, en caso de faltar la culpabilidad ya no es posible considerar el hecho como acción. La imputación

\footnotetext{
${ }^{23}$ Esta vinculación entre pena como respuesta al hecho de una persona libre también la encontramos en Jakobs. Para este autor la culpabilidad en el ámbito del Derecho se determina de manera general-normativa, es decir en cuanto sujeto que se define como ciudadano. La culpabilidad no es otra cosa que una falta de fidelidad al derecho por parte del autor (en su rol de ciudadano). Mientras Jakobs, en el tratamiento de Schuldund Prävention (Culpabilidad y prevención) (1976), la interpretación preventiva y justificación jurídica del concepto de culpabilidad relacionaba explícitamente al sistema jurídico del momento y por ello la legitimidad ya estaba implícita en la orden, cuya estabilización debía ser la finalidad de la pena y de la imputación, Jakobs diferencia explícitamente en el tratamiento de Das Schuldprinzip (El principio de culpabilidad)(1993) un concepto formal de culpabilidad válido para cualquier orden, de un concepto material que se encuentra sólo en órdenes legítimas. A partir de este momento el concepto de culpabilidad en Jakobs tiene un sentido material que va más allá del contenido meramente formal consistente en la afirmación de la culpabilidad como medio para garantizar la estabilidad social. El contenido material de la culpabilidad se manifiesta en la medida en que el delito es interpretado como una perturbación proveniente de una persona, no de un animal o cosa. La imputación vincula el suceso entendido como un esbozo de la realidad, y la pena como contradicción del esbozo de sociedad representado por el autor, considerando a éste en tanto persona. En este sentido, Jakobs recurre a Hegel al afirmar que solamente considerando al delincuente como persona pueden comprenderse el hecho y la pena como contexto de sentido y no como secuencia irracional de dos males (1993: 26-27). Según Jakobs la imputación a la persona significa que la misma es aislada de una multitud de posibles causas y circunstancias que pueden explicar la defraudación de la expectativa. La persona debe ser constituida de manera que la imputación esté relacionada a algo, a una motivación, que sólo puede ser asignada a la persona misma.La defraudación de la expectativa puede, entonces, ser explicada de manera que su causa se basa en la motivación errónea, o sea, en la motivación no conforme a derecho, en un defecto en el respeto de la norma, por lo cual la persona es responsable (Günther, 2005: 43-44).
} 
Cordini, N. S. Delito y pena en la teoría de la imputación según Hegel. Derecho y Ciencias Sociales. Noviembre 2019 - Abril 2020 N ${ }^{\circ}$ 22. Pgs 18 - 39 ISNN 1852-2971 Instituto de Cultura Jurídica y Maestría en Sociología Jurídica. FCJ y S. UNLP

objetiva y la imputación a la culpabilidad no son estrictamente divididas la una de la otraen imputatiofacti e imputatiouiris, conforme a las teorías de la imputación imperantes en ese periodo, sino comprehendidas mutuamente 0 , en otros términos, sus elementos son mezclados en un solo juicio. El concepto hegeliano de ilícito, en cierto sentido y hasta determinado grado, simpatiza con los fundamentos inmanentes de la culpabilidad. Las distinciones entre imputatiofacti e imputatio iuris se disuelven en una suerte de applicatiolegis adfactum (aplicación de la ley al hecho),o mejor, de aplicación de lo general a lo particular por el sujeto imputante. La imputación se dirige a constatar la subsunción, o no, de la voluntad, de lo particular en lo general, lo racional. Esta medición desplaza la dualidad de los juicios de imputación (Sáchnez-Ostíz, 2008: 286).

Hegel ha marcado con su concepto de dolo aquello que puede ser atribuido al sujeto como acción. Por lo tanto, sería una interpretación demasiado forzada intentar extender los presupuestos de la imputación al ámbito del actuar imprudente. La imputación sólo hace alusión a la conducta dolosa, no pudiendo ser extendida al actuar imprudente. Sólo las consecuencias del hecho dominadas a través de la finalidad de la acción pueden ser imputadas y, por lo tanto, forman con la acción una totalidad. Por lo demás, como Hegel subraya, el autor debe haber presupuesto las consecuencias no individualmente; es suficiente que él conozca la naturaleza general del hecho. Con la acción como totalidad se le pueden imputar, a título de dolo, las consecuencias particulares necesarias.

Según el modelo analizado, existe un sinalagma entre libertad y culpabilidad penal, entre delito y pena pues, desde la perspectiva hegeliana, quien se arroga un espacio de libertad (libertad de organización) para su autogestión se hace cargo, simultáneamente, de la responsabilidad por las consecuencias de la gestión deficiente. La pena no hace sino restaurar el orden lesionado y, al mismo tiempo, "honra al delincuente en tanto ser racional" (Hegel, 1820: 100, 90), puesto que su hecho es interpretado como una formal racional voluntad particular. En términos de Hegel:

"[s]iendo [...] el autor un ser racional, en su acción se denota una generalidad. Si robas a otro, te robas a ti mismo. Si matas a alguien, así matas tu a todos y a ti mismo. La acción es una ley, que tú eriges y que tú, a través de tu actuar, en y para sí has reconocido. El infractor debe por eso subsumirse para sí bajo el mismo de proceder que él ha erigido, y así se restaura la igualdad por él lesionada: iustalionis" (1986b: §20: 244). 
Cordini, N. S. Delito y pena en la teoría de la imputación según Hegel. Derecho y Ciencias Sociales. Noviembre 2019 - Abril 2020 N ${ }^{\circ}$

22. Pgs 18 - 39 ISNN 1852-2971 Instituto de Cultura Jurídica y Maestría en Sociología Jurídica. FCJ y S. UNLP

\section{Bibliografía}

Bubnoff, E. (1966). Die Entwicklung des strafrechtlichen Handlungsbegriffes von Feuerbach bis Liszt unter besonderer Berücksichtigung der Hegelschule, Heidelberg: Carl Winter Universitätsverlag.

Flechtheim, O. K. (1975).Hegels Straftheorie. Berlín: Duncker \& Humblot.

Günther, K. (2005). Schuld und kommunikative Freiheit. Studienzurpersonale Zurechnungstrafbaren Unrechtsim demokratischen Rechtstaat. Frankfurt am Main: Vittorio Klostermann.

Hardwig, W. (1957). Die Zurechnung. Ein Zentralproblem des Strafrechts. Hamburg: Gruyter \& Co.

Hegel, G. W. F. (1986a).Vorlesungen über Geschichte der Philosophie I. Tomo 18, Frankfurt a. M.: Suhrkamp Verlag, 1970.

Hegel, G. W. F. (1986b) Nürnberger und Heidelberger Schriften, Tomo 4, Frankfurt a. M.: Suhrkamp Verlag.

Hegel, G. W. F. (1830a). Enzyklopädie der philosophischen Wissenschaften im Grundrisse. Erster Teil. Die Wissenschaft der Logik mit den mündlichen Zusätzen, Frankfurt a. M.: Suhrkamp Verlag, 1970.

Hegel, G. W. F.(1830b). Enzyklopädie der philosophischen Wissenschaften im Grundrisse. Zweiter Teil. Die Wissenschaft der Logik mit den mündlichen Zusätzen, Frankfurt a. M., Suhrkamp Verlag, 1986.

Hegel, G. W. F.(1830c). Enzyklopädie der philosophischen Wissenschaften im Grundrisse. Dritter Teil. Die Wissenschaft der Logik mit den mündlichen Zusätzen, Frankfurt a. M., Suhrkamp Verlag, 1990.

Hegel, G. W. F. (1820).Grundlinien der Philosophie des Rechts oder Naturrecht und Staatswissenschaft im Grundrisse. Leipzig: Felix Meiner, 1911.

Hegel, G. W. F. (1817). Enzyklopädie der philosophischen Wissenschaften im Grundrisse. Heidelberg: August Oßwald's Universitätsbuchhandlung.

Hösle, V. (1988). Hegels System. Der Idealismus der Subjektivität und das Problem der Intersubjektivität. $2^{\text {a }}$ edición, Hamburgo: Meiner, 1998.

Hruschka, J. (1976). Strukturen der Zurechnung, 1. Auflage, Berlin-New York: Walter de Gruyter.

Hruschka, J. (1991).”Verhaltensregeln und Zurechnungsregeln“.Rechtstheorie. vol. 22, pp. 449-460. 
Cordini, N. S. Delito y pena en la teoría de la imputación según Hegel. Derecho y Ciencias Sociales. Noviembre 2019 - Abril 2020 N ${ }^{\circ}$

22. Pgs 18 - 39 ISNN 1852-2971 Instituto de Cultura Jurídica y Maestría en Sociología Jurídica. FCJ y S. UNLP

Jakobs, G. (2012). System der strafrechtlichen Zurechnung. Frankfurt am Main: Vittorio Klostermann.

Jakobs, G. (1997). “El concepto jurídico-penal de acción”, en Estudios de Derecho penal, traducción de Manuel Cancio Meliá, Madrid: Civitas, pp. 101-125.

Jakobs, G. (1993). Das Schuldprinzip. Düsseldorf: Westdeutscher Verlag.

Jakobs, G. (1976). Schuld und Prävention. Tübingen: J.C.B. Mohr (Paul Siebeck).

Jakobs, G. (1991). Strafrecht, Allgemeiner Teil: die Grundlagen und die Zurechnungslehre. Lehrbuch. $2^{\text {a }}$ edición, Berlin-New York: Walter de Gruyter.

Jermann, C. (1987).“Die Moralität", en: Jermann, C. (ed) Anspruch und Leistung von Hegels Rechtsphilosophie. Stuttgart-Bad Cannstadt: Frommann Holzboog, pp. 101-144.

Kant, I. (1797).’Die Metaphysik der Sitten“, en: Kant's gesammelte Schriften, Berlín: Walter de Gruyter, VI, 1907, pp. 203-492.

Klesczewski, D. (1990). Die Rolle der Strafe in Hegels Theorie der bürgerlichen Gesellschaft. Eine systematische Analyse des Verbrechens- und des Strafbegriffs in Hegels Grundlinien der Philosophie des Rechts. Berlín: Dunker \& Humblot.

Larenz, K. (1930). "Staat und Religion bei Hegel. Ein Beitrag zur systematischen Interpretation der Hegelschen Rechtsphilosophie“, en: Larenz, K., et al, (comps) Rechtsidee und Staatsgedanke. Beinträge zur Rechtsphilosophie und zur politischen Ideengeschichte. Festgabe für Julius Binder. Berlín: Junker, pp. 243-263.

Larenz, K. (1927). Hegels Zurechnungslehre und der Begriff der objektiven Zurechnung. Ein Beitrag zur Rechtsphilosophie des kritischen Idealismus und zur Lehre von der ,juristischen Kausalität, Leipzig: Werner Scholl.

Lesch, H. (2001). Injusto y culpabilidad en Derecho penal. Bogotá: Universidad Externado de Colombia.

Lesch, H. (1999a). Der Verbrechensbegriff: Grundlinien einer funktionalen Revision, KölnBerlin-Bonn-München: Carl Heymanns.

Lesch, H. (1999b). La función de la pena, traducción de Javier Sánchez-Vera- GómezTrelles, Madrid; Dykinson.

Lesch, H. (1995). "Intervención delictiva e imputación objetiva", ADPCP, T. XLVIII, Fasc. III, Septiembre-Diciembre, pp.911-972.

Marmasse, G. (2004). "Qui est coupable ? Action et imputation chez Hegel”, en :Kervégan, J-F, Marmasse, G. (directores) Hegel penseur du droit. Paris: CNRS éditions, 2004, pp. 113-129. 
Cordini, N. S. Delito y pena en la teoría de la imputación según Hegel. Derecho y Ciencias Sociales. Noviembre 2019 - Abril 2020 N ${ }^{\circ}$

22. Pgs 18 - 39 ISNN 1852-2971 Instituto de Cultura Jurídica y Maestría en Sociología Jurídica. FCJ y S. UNLP

Mayer, H. (1969)."Kant, Hegel und das Strafrecht", en: Bockelmann, P., et al (eds) Festschrift für Karl Englisch zum 70. Geburtstag. Frankfurt a. M.: Vittorio Klostermann, pp. 54-79

Merle, J-C. (2003). „Was ist Hegels Straftheorie?“, Jahrbuch für Recht und Ethik, pp. 145176.

Pawlik, M. (2012). Das Unrecht des Bürgers. Grundlinien der Allgemeinen Verbrechenslehre. Heidelberg: Mohr Siebeck

Radbruch, G. (1903).Der Handlungsbegriff in seiner Bedeutung für das Strafrechtssystem. Zugleich ein Beitrag zur Lehre von der rechtswissenschaftlichen Systematik. Berlín: J. Guttentag Verlagsbuchhandlung.

Sánchez-Ostíz, P.(2008). Imputación y teoría del delito. La doctrina kantiana de la imputación y su recepción en el pensamiento jurídico-penal. Montevideo-Buenos Aires: B de F.

Seelmann, K. (2007) „Anerkennung, Person, Norm“, en: Pawlik, M. et al (eds), Festschrift für Günther Jakobs zum 70. Geburtstag am 26. Juli 2007. Berlin: Carl Heymanns, 2007, pp. 635-644.

Schild, W. (1981). „Der strafrechtsdogmatische Begriff der Zurechnung in der Rechtsphilosophie Hegels“. ZfPhF 35, pp. 445-476.

Schumacher, H. (1985). Hegels Rechtsphilosophie. Hagen: Kurs der Fernuniversität Gesamthochschule - in Hagen.

Welzel, H. (2005).Introducción a la filosofia del derecho. Derecho natural y justicia material. Buenos Aires: B de F.

Welzel, H. (1935). NaturalismusundWertphilosophieimStrafrecht. Untersuchenüber die ideologischenGrundlagen der Strafrechtwissenschaft". Mannheim-Berlin-Leipzig: DeutschesDruck- undVerlagshaus.

Wood, A. W. (1990). Hegel Ethical's Thought, New York, Cambridge University Press. 